\title{
INTERPROFESIONAL COLABORATION SEBAGAI WADAH DALAM UPAYA MENINGKATKAN KESELAMATAN PASIEN
}

\author{
ANGEL OKTAVIA PURBA / 181101099 \\ angeloktavia013@gmail.com
}

\begin{abstract}
ABSTRAK
Interprofessional Colaboration (IPC) adalah kemitraan antara orang dengan latar belakang profesi yang berbeda dan bekerja sama untuk memecahkan masalah kesehatan dan menyediakan pelayanan kesehatan (Morgan et al, 2015). Adapun tujuan Interprofessional colaboration (IPC) sebagai wadah dalam upaya mewujudkan praktik kolaborasi yang efektif antar profesi sehingga dengan adanya kolaborasi antar profesi di RS dapat mendukung kesehatan dan keselamatan pasien.Adapun tujuan dari penulisan ini adalah agar dapat mengetahui apa itu defenisi interprofesional colaboration (IPC). Mengetahui tujuan dari interprofesional collaboration dan bagaimana strategi meningkatkan keselamatan pasien dengan metode interprofesional colaboration (IPC). Metode penulisan ini adalah Literature Riview, dimana ini menganalisis artikel yang relevan dan berfokus pada tema yaitu Interprofesional collaboration dengan keselamatan pasien.
\end{abstract}

Kata Kunci : Interprofesional Colaboration, Keselamatan Pasien, Komunikasi efektif.

\begin{abstract}
Interprofessional Colaboration (IPC) is a partnership between people from different professional backgrounds and working together to solve health problems and provide health services (Morgan et al, 2015). The purpose of Interprofessional colaboration (IPC) as a forum in an effort to realize effective collaboration practices between professions so that collaboration between professions in hospitals can support the health and safety of patients. The purpose of this paper is to be able to find out what is the definition of interprofessional colaboration (IPC). Know the purpose of interprofessional collaboration and how strategies improve patient safety with the method of interprofessional colaboration (IPC). This writing method is Riview Literature, where it analyzes relevant articles and focuses on the theme of Interprofessional colaboration with patient safety.
\end{abstract}




\section{LATAR BELAKANG}

Seiring perkembangan di dalam dunia kesehatan Peningkatan permasalahan pasien yang kompleks membutuhkan keterampilan dan pengetahuan dari beberapa tenaga profesional. Oleh karena itu kerjasama dan kolaborasi yang baik antar profesi kesehatan sangat dibutuhkan untuk meningkatkan kepuasan pasien dalam melakukan pelayanan kesehatan. Pelayanan kesehatan yang diberikan di rumah sakit dilakukan oleh berbagai profesi tenaga kesehatan.Tujuan: Penulisan ini bertujuan untuk mengetahui dan memberi informasi tentang peningkatan interprofessional collaboration dalam menjalankan program keselamatan pasien. Peningkatan permasalahan pasien yang kompleks membutuhkan keterampilan dan pengetahuan dari beberapa tenaga profesional. Oleh karena itu kerjasama dan kolaborasi yang baik antar profesi kesehatan sangat dibutuhkan untuk meningkatkan kepuasan pasien dalam melakukan pelayanan kesehatan. Pendekatan kolaborasi yang masih berkembang saat ini yaitu interprofessional collaboration (IPC) sebagai wadah dalam upaya mewujudkan praktik kolaborasi yang efektif antar profesi. Terkait hal itu maka perlu diadakannya praktik kolaborasi sejak dini dengan melalui proses pembelajaran yaitu dengan melatih mahasiswa pendidikan kesehatan. IPC merupakan wadah kolaborasi efektif untuk meningkatkan pelayanan kesehatan kepada pasien yang didalamnya terdapat profesi tenaga kesehatan meliputi dokter, perawat, farmasi, ahli gizi, dan fisioterapi (Health Professional Education Quality (HPEQ), 2011). Tenaga kesehatan harus melakukan praktek kolaborasi dengan baik dan tidak melaksanakan pelayanan kesehatan sendirisendiri. Praktek kolaborasi dapat menurunkan angka komplikasi, lama rawat di rumah sakit, konflik diantara tim kesehatan, dan tingkat kematian serta di bidang kesehatan mental, praktek kolaboratif dapat meningkatkan kepuasan pasien dan tim kesehatan, mengurangi durasi pengobatan, mengurangi biaya perawatan, mengurangi insiden bunuh diri, dan mengurangi kunjungan rawat jalan.

\section{TUJUAN}

Adapun tujuan dari penulisan ini adalah agar dapat mengetahui apa itu defenisi interprofesional collaboration (IPC). Mengetahui tujuan dari interprofesional collaboration dan bagaimana strategi meningkatkan keselamatan pasien dengan metode interprofesional colaboration (IPC).

\section{METODE}

Metode penulisan ini adalah Literature Riview, dimana ini menganalisis artikel yang relevan dan berfokus pada tema yaitu Interprofesional collaboration dengan keselamatan pasien. Adapun sumber yang digunakan dalam literature ini menggunakan sumber dari buku teks, jurnal dengan memasukan kata kunci interprofesional collaboration dengan keselamatan pasien. Adapun jurnal yang saya yang digunakan merupakan jurnal yang diiterbitkan pada 10 tahun terakhir. 


\section{HASIL}

Berdasarkan pencarian literature didapatkan apa defenisi interprofesional colaboration, apa tujuan dilakukannya interprofesional colaboration dan bagaimana strategi meningkatkan keselamatan pasien dengan metode interprofesional colaboration (IPC).

\section{PEMBAHASAN}

Interprofessional Colaboration (IPC) adalah kemitraan antara orang dengan latar belakang profesi yang berbeda dan bekerja sama untuk memecahkan masalah kesehatan dan menyediakan pelayanan kesehatan (Morgan et al, 2015). Menurut WHO, IPC terjadi saat berbagai profesi kesehatan bekerja sama dengan pasien, keluarga dan komunitas untuk menyediakan pelayanan komprehensif dan berkualitas tinggi (WHO, 2010). IPC dimaksudkan untuk mencapai tujuan dan memberi manfaat bersama bagi semua yang terlibat (Green and Johnson, 2015). Rumah sakit sebagai institusi yang memberikan pelayanan kesehatan yang menyediakan pelayanan melalui rawat jalan, rawat inap dan gawat darurat. Pelayanan kesehatan yang paripurna menurut UU nomor 44 tahun 2009 pasal 1 ayat 3 adalah pelayanan yang meliputi pelayanan promotif, preventif, kuratif dan rehabilitatif. Pelayanan kesehatan yang diberikan di rumah sakit dilakukan oleh berbagai profesi tenaga kesehatan. Berbagai profesi yang terlibat dalam pelayanan kesehatan terdiri dari tenaga medis, tenaga psikologi klinis, tenaga keperawatan, tenaga kebidanan, tenaga kefarmasian, tenaga gizi, tenaga keterapian fisik, tenaga keteknisian medis dan teknik biomedika (UU Nomor 36 tahun 2014). Pelayanan kesehatan di rumah sakit merupakan pelayanan dari berbagai profesi kesehatan yang berkolaborasi untuk mengoptimalkan pelayanan kesehatan (Sitorus, 2006). Adapun tujuan Interprofessional collaboration (IPC) sebagai wadah dalam upaya mewujudkan praktik kolaborasi yang efektif antar profesi. Terkait hal itu maka perlu diadakannya praktik kolaborasi dengan profesi lainnya. IPC merupakan wadah kolaborasi efektif untuk meningkatkan pelayanan kesehatan kepada pasien yang didalamnya terdapat profesi tenaga kesehatan meliputi dokter, perawat, farmasi, ahli gizi, dan fisioterapi (Health Professional Education Quality (HPEQ), 2011). Kerjasama dan kolaborasi yang baik antar profesi kesehatan sangat dibutuhkan untuk meningkatkan kepuasan pasien dalam melakukan pelayanan kesehatan. Dalam melakukan peningkatan IPC dapat dilakukan dengan cara yaitu peningkatan komunikasi yang efektif. Dengan komunikasi yang efektif Sehingga 
para tenaga kesehatan dapat melakukan tindakan pelayanan kesehatan yang aman dan efektif. IPC menjadi hal yang penting untuk setiap tenaga kesehatan dikarenakan dengan adanya interprofesional collaboration maka semua tenaga kesehatan yang ada di rumah sakit dapat menjalin komunikasi yang baik sehingga dengan terlajinnya kolaborasi yang baik maka dapat meningkatkan keselamatan dan kesehatan pasien.

\section{KESIMPULAN}

Interprofessional Collaboration (IPC) adalah kemitraan antara orang dengan latar belakang profesi yang berbeda dan bekerja sama untuk memecahkan masalah kesehatan dan menyediakan pelayanan kesehatan (Morgan et al, 2015). Adapun tujuan Interprofessional collaboration (IPC) sebagai wadah dalam upaya mewujudkan praktik kolaborasi yang efektif antar profesi sehingga dengan adanya kolaborasi antar profesi di RS dapat mendukung kesehatan dan keselamatan pasien.

\section{SARAN}

Perawat sebagai suatu profesi tidak dapat menjalankan tugasnya tanpa adanya kolaborasi dengan tenaga medis atau profesi lain yang ada di Rumah Sakit, untuk itu diharapkan perawat dapat melakukan interprofesional collaboration dengan profesi atau tenaga mesis lainnya agar dapat meningkatkan derajat keselamatan dan kesehatan pasien di RS.

\section{DAFTAR PUSTAKA}

Basabih, Masyitoh. (2017).Perlukah Keselamatan Pasien Menjadi Indikator Kinerja RS. BLU ?. Jurnal Administrasi Rumah Sakit Indonesia. 3(2): 150-157.

Darliana, D. (2016). Hubungan Pengetahuan Perawat dengan Upaya Penerapan Patient Safety di Ruang Rawat Inap RSUD Dr. Zainoel Abidin Banda Aceh. Idea Nursing Journal. 7(1): 62-63.

Departemen Kesehatan RI. (2008). Upaya Peningkatan Mutu Pelayanan Rumah Sakit. Jakarta: Depkes RI.

Efendi, Ferry, dan Makhfudli. (2009). Keperawatan Kesehatan Komunitas :Teori dan Praktik Dalam Keperawatan. Jakarta : Salemba Medika.

Firawati. (2012). Pelaksanaan Program Keselamatan Pasien di RSUD Solok. Jurnal Kesehatan Masyarakat. 6(2): 74- 77.

Ismainar, Hetty. (2015). Keselmatan Pasien di Rumah Sakit. Yogyakarta: Deepublish. 
Kemenkes RI. (2011). Peraturan Menteri Kesehatan Republik Indonesia Nomor1691/MENKES/PER/VIII/2011

tentang Keselamatan Pasien Rumah Sakit. Jakarta: Depkes RI.

Lestari, Yani (2017). Hubungan Interprofesional Kolaborasi Dengan Pelaksanaan Catatan Perkembangan Pasien Terintegrasi DI RSUD. PROF. DR. H.M. Anwar Makkatutu Kabupaten Bantaeng. JST Kesehatan Vol. 7 No. 1 : 85-90.

Permenkes RI. (2011). Peraturan Menteri Kesehatan Republik Indonesia Nomor 1691/Menkes/Per/VIII/2011 Tentang Keselamatan Pasien Rumah Sakit. Jakarta: Depkes RI.

Permenkes RI. (2017). Peraturan Menteri Kesehatan Republik Indonesia Nomor 34 Tahun 2017 Tentang Akreditasi Rumah Sakit. Jakarta: Depkes RI.

Rokhmah.N.A. (2017). Komunikasi Efektif Dalam Praktek Kolaborasi Interprofesional Sebagai Upaya Meningkatkan Kualitas Pelayanan. Journal Of Health Studies, vol 1(1), 65-71.

Simamora. R.H. (2019). Buku Ajar Pelaksanaan Identifikasi Pasien : Uwais Inspirasi Indonesia.

Simamora. R.H. (2019). Documentation Of Patient Identification Into The Electronic
System to Improve the Quality of Nursing Service. Internasional Journal Of Sciiebtific \& Technology Research, Vol 08(09),18841886.

Simamora. R.H. (2019). The Influence Of Training Handover Based SBAR Communication For Improving Patients Safety. Indian Journal of Public Health Research \& Development, Vol 09, 12801285.

Triana,Neny.2018 .Interprofesional Education di Institusi Dan Rumah Sakit. Jakarta:Deepulisher Publish.

Tutiany, Lindawati, Krisanti P. (2017). Bahan Ajar Keperawatan: Manajemen Keselamatan Pasien. Jakarta: Kemenkes RI.

Ulumiyah, Nurul H. (2018). Meningkatkan Mutu Pelayanan Kesehatan Dengan Penerapan Upaya Keselamatan Pasien di Puskesmas. Jurnal Administrasi Kesehatan Indonesia, 150-154.

Wardhani,Viera.2017.Manajemen Keselamatan Pasien.Malang:UB Press. 
